\title{
An Experimental Study of Thermal Comfort in a Main Line Vehicle during Winter
}

\author{
H. Endoh ${ }^{1}$, Y. Izumi ${ }^{1}$ and N. Hayashi ${ }^{2}$ \\ ${ }^{1}$ Railway Technical Research Institute, Tokyo, Japan \\ ${ }^{2}$ East Japan Railway Company, Saitama, Japan
}

\begin{abstract}
The relation between the thermal environment and thermal comfort of passengers in a main line rail carriage was investigated. Field measurements and a subjective experiment were performed. Field studies measured the temperature and humidity in main line vehicles during regular passenger service, and their variation was investigated. In the subjective experiment, nineteen subjects wearing identical clothing were placed in a sitting position in a static main line vehicle and were asked to record their thermal comfort level. Based on the results, regression equations linking thermal comfort to the Standard New Effective Temperature Index were derived, and a comparison was made with earlier studies conducted in a climatic chamber.
\end{abstract}

Keywords: thermal environment, thermal comfort, main line vehicle, field measurement, subjective experiment, comfort range, Standard New Effective Temperature, Predicted Mean Vote, Predicted Percentage of Dissatisfied.

\section{Introduction}

A range of factors affects passengers' comfort in railway vehicles, and earlier studies have identified thermal comfort as one of the most important factors [1]. Although the thermal environment in modern railway vehicles is controlled by air-conditioning systems, many complaints from passengers about thermal comfort are received every year. To improve the passenger environment, a deeper understanding of the characteristics of thermal comfort from the point of view of the passenger is essential.

Standards exist to regulate the thermal environment in railway vehicles. For example, EN 13129 [2] specifies measurement methods and comfort ranges. However, current standards do not specify quantitative thermal comfort evaluation methods. Different individuals have different thermal characteristics, so that each 
passenger will experience the same environment differently. When evaluating the thermal environment in a railway vehicle, it is important to take this variability into account, for example by measuring the proportion of passengers who feel thermally uncomfortable and dissatisfied. However, there is currently no established method for providing such information.

A considerable number of studies have been made on thermal comfort in the indoor environment of buildings [3, 4], and evaluation indices have been proposed. The two most popular indices are the Predicted Mean Vote (PMV), which predicts the average thermal sensation of people exposed to the same thermal environment, and the Predicted Percentage of Dissatisfied (PPD), which predicts the percentage of people who will be thermally uncomfortable. These PMV and PPD indices are specified in ISO 7730 [5]. Another popular index is the Standard New Effective Temperature $\left(\mathrm{SET}^{*}\right)$, which represents the sensory temperature (in units of ${ }^{\circ} \mathrm{C}$ ) calculated from a human thermal model [4]. Many laboratory tests and field surveys have examined the relation between the $\mathrm{SET}^{*}$ and thermal comfort of individuals. Based on the results, ASHRAE has proposed a comfort range in which $20 \%$ of people find the environment thermally unacceptable, corresponding to an SET ${ }^{*}$ range from 22.2 to $25.6{ }^{\circ} \mathrm{C}$ [6].

Many field measurements and thermal comfort studies were performed in mass transportation vehicles, and the PMV/PPD and SET* were used to evaluate passenger thermal comfort. Pang et al. [7] conducted a field thermal comfort survey in aircraft cabins, collecting cabin environmental data from 31 flights. They developed a corrected PMV model for low pressure and relative humidity in aircraft cabins and assessed the thermal comfort conditions for the 31 flights investigated. Their results indicated that thermal comfort was not controlled very well in some flights, especially in some short-haul flights, and that there were some cases of overheating or undercooling. Zhang et al. [8] assessed thermal comfort in buses based on the PPD. According to their results, passengers in buses felt thermally comfortable when the PPD is less than 23\%. Pala and Oz [9] developed a standard testing and computational model for bus HVAC design and conducted an assessment of a bus HVAC system either for heating or cooling. The computational model was based on the two-node model (human thermal model) which was also used to calculate the SET ${ }^{*}$. Lin et al. [10] conducted a field investigation involving simultaneous physical measurements and a questionnaire survey and evaluated thermal comfort in short- and long-haul buses and trains. They observed that the neutral temperatures for short- and long-haul vehicles are $26.2^{\circ} \mathrm{C}$ and $27.4{ }^{\circ} \mathrm{C}$, respectively, and the corresponding comfort zones are $22.4-28.9{ }^{\circ} \mathrm{C}$ and $22.3-30.1{ }^{\circ} \mathrm{C}$, respectively. Katavoutas et al. [11] performed field measurements in the interior of two types of subway trains (air-conditioned and forced air ventilation cabins) during summer and estimated thermal comfort by using the PMV/PPD. In air-conditioned cabins, the average PPD ranged $23-26 \%$, whereas in forced air ventilation cabins this percentage was $77 \%$. Underwood and Parsons [12] investigated the effects on thermal comfort of sitting 'side-on' to a cold window and reported that the PMV provides a reasonably predictive index. 
As described above, the thermal indices (PMV/PPD and SET*) are used to assess passenger thermal comfort and to clarify the comfort range for the thermal environment in vehicles. However, it should be noted that those indices were originally developed with the assumption of uniform and stationary thermal conditions. Therefore, when the thermal environment in a vehicle is non-uniform and non-stationary, the prediction error of thermal comfort may become large. Kelly [13] conducted measurements of thermal factors and subjective evaluations in simulated train environments and observed overshoots in sensation following downward steps (warmer to cooler) in environmental conditions; the PMV may estimate a thermal sensation that is warmer than the actual sensation that a person feels when moving from a warmer environment to cooler one. Recently, regarding the thermal comfort in non-uniform and non-stationary conditions, many experimental studies $[14,15]$ and simulation studies were performed [16, 17]. Konstantinov and Wagner [18] used computational fluid dynamics to perform numerical simulations on non-uniform and non-stationary thermal environments in a train cabin and analysed the thermal comfort of passengers.

It should also be noted that passenger thermal comfort would not only be affected by non-uniformity and non-stationarity of the thermal environment, but also by expectations that passengers set for the thermal environment and seasonal changes in the human thermo-regulation system. Nakano et al. [19] conducted a survey on a station platform and reported differences between the actual percentage of dissatisfied passengers and the PPD. This result indicates that passengers' expectations of the thermal environment in railway vehicles may differ from occupants' one in buildings. Nakayama [20] reported seasonal changes of thermo-regulation system of Japanese. Fukai et al. [21] investigated the relation between the SET ${ }^{*}$ and thermal sensation and comfort in a climatic chamber in winter and summer and found that thermal sensation did not significantly vary, but that thermal comfort was dependent on the season. Therefore, for thermal comfort evaluations of passengers in Japan, passenger expectations of thermal environment in the vehicle and seasonal characteristics of thermal comfort, should be considered. However, very few studies have considered these factors.

In some field studies, both environmental and subjective data were simultaneously gained and the relations between calculated PMV/PPD and actual thermal sensation/comfort votes were analysed. However, in such studies, the amount of clothing and activity levels were difficult to estimate accurately, and this lack of accuracy may cause a large calculation error in the PMV/PPD. Moreover, in operating vehicles, non-uniformity and non-stationarity of the thermal environments as well as noise and vibrations may influence the thermal comfort of passengers. These factors cannot be taken into consideration in the PMV/PPD model. By contrast, with climatic chamber tests, the amount of clothing and the activity levels can be controlled and the effects of the vibration and noise can be eliminated. However, the subjects find it difficult to imagine realistic sensations of a train journey and to reflect their expectations for thermal environments in a train vehicle on their subjective ratings. 
Currently, there are few fundamental data about the relation between the passengers' subjective expectation for the thermal environment in train vehicles and the thermal indices calculated by precise input values, especially regarding the amount of clothing and activity levels. This data would contribute to the accurate prediction of thermal comfort of passengers and the appropriate assignment of comfort ranges.

Therefore, the aim of this study is to clarify the relationship between the subjective data reflecting passengers' expectations in train vehicles and calculated thermal indices (PMV/PPD, SET*), and to examine the comfort range of thermal environments.

In this study, a subjective experiment was conducted in an actual train vehicle to provide the realistic sensation of a train journey to the subjects and to reflect the expectation for the thermal environment on the subjective ratings. To reduce calculation errors of the thermal indices, the amount of clothing and activity levels of the subjects were unified. To eliminate the effects of noise, vibrations and radiation asymmetry (one of the non-uniformity factors of thermal environments), the vehicle was stationed in a train shed. The temperature condition in the subjective experiments was designed referring to the results of the field measurements conducted before the experiment. Based on the experimental results, the relation between the SET ${ }^{*}$ and thermal comfort was analysed, and a regression function for predicting passenger thermal comfort was derived. The results of the subjective experiment were compared with those of previous studies on the indoor environment of buildings, and the influence of place and season on thermal comfort was examined.

The final goal of our research is to develop an evaluation method for thermal comfort that is applicable to a railway vehicle in Japan across all seasons. This paper reports a first step of our research which focused on the thermal environment in main line vehicles in winter.

Our overall approach followed that of Endoh et al. [22], but was expanded as follows: (1) a comparison was made with previous studies, including Gagge's survey [23] of a New York government building from which the comfort range of the SET* was derived [24], and Fukai's laboratory experiments [21], in which the relationship between the SET ${ }^{*}$ and Japanese thermal comfort was investigated, and (2) the application of the PPD index to a passenger cabin in a main line vehicle in winter in Japan was investigated.

\section{Field measurements in a main line vehicle}

In the winter of 2014, field measurements were conducted of temperature and humidity on a main line vehicle during regular passenger service. The surveys ran for five days, from morning services with a departure time of 7:30 and an arrival time of 11:00 to night time services departing at 18:50 and arriving at 21:10. Ten trips were investigated, with a total time of approximately three hours per trip. Table 1 shows the departure and arrival times and the outdoor environment conditions. 


\subsection{Methods}

The thermal environment in the vehicle at standstill was measured prior to the fieldwork. The maximum and minimum temperatures were found near the centre and ends of the vehicle, respectively. In the field study, these two positions were used as the measurement points to record horizontal temperature differences in the vehicle.

\begin{tabular}{|c|c|c|c|c|c|c|c|l|}
\hline \multirow{2}{*}{ No } & \multirow{2}{*}{ Departure } & \multirow{2}{*}{ Arrival } & \multicolumn{3}{|c|}{ At the time of departure } & \multicolumn{3}{c|}{ At the time of arrival } \\
\cline { 4 - 9 } & & $\begin{array}{c}\text { Temperature } \\
{\left[{ }^{\circ} \mathrm{C}\right]}\end{array}$ & $\begin{array}{c}\text { Humidity } \\
{[\% \mathrm{rh}]}\end{array}$ & Weather & $\begin{array}{c}\text { Temperature } \\
{[\mathrm{oC}]}\end{array}$ & $\begin{array}{c}\text { Humidity } \\
{[\% \mathrm{rh}]}\end{array}$ & Weather \\
\hline 1 & $13: 00$ & $16: 30$ & 9.7 & 35 & Sunny & 2.1 & 58 & Sunny \\
\hline 2 & $17: 40$ & $21: 10$ & 2.7 & 52 & Sunny & 9.2 & 56 & Cloudy \\
\hline 3 & $7: 30$ & $11: 10$ & 4.9 & 90 & Raining & 6.0 & 52 & Cloudy \\
\hline 4 & $11: 40$ & $15: 10$ & 6.0 & 52 & Cloudy & 6.3 & 91 & Raining \\
\hline 5 & $12: 00$ & $15: 10$ & 6.7 & 21 & Cloudy & -1.8 & 41 & Cloudy \\
\hline 6 & 16.15 & $19: 50$ & -2.2 & 46 & Cloudy & 5.0 & 26 & Sunny \\
\hline 7 & $13: 00$ & $15: 20$ & 9.8 & 29 & Sunny & -0.4 & 52 & Snowing \\
\hline 8 & $18: 50$ & $21: 10$ & -2.8 & 72 & Snowing & 7.0 & 30 & Sunny \\
\hline 9 & $13: 00$ & $16: 30$ & 8.7 & 34 & Sunny & 2.0 & 61 & Cloudy \\
\hline 10 & $17: 40$ & $21: 10$ & -0.1 & 92 & Snowing & 7.4 & 69 & Cloudy \\
\hline
\end{tabular}

Table 1: Departure/arrival time and outdoor environment conditions

Investigators equipped with pouches containing a thermometer and a hygrometer were seated near the centre and the ends of the cabin. The pouches were placed on the floor, the seat table and the baggage rack, providing measurements at about $0.1,0.8$ and $1.7 \mathrm{~m}$ from the floor. The temperature was measured using a thermistor (sensor: TR-1106; logger: TR71Ui, T\&D; accuracy: $\pm 0.5{ }^{\circ} \mathrm{C}$ at $-40{ }^{\circ} \mathrm{C}$ to $80{ }^{\circ} \mathrm{C}$ ) at intervals of 5 s. Humidity was measured using a resistance-type humidity sensor (sensor: TR3110; logger: TR72Ui, T\&D; accuracy: $\pm 5 \%$ rh at $25^{\circ} \mathrm{C}, 50 \%$ rh) at intervals of $5 \mathrm{~s}$.

\subsection{Results}

Figure 1 shows examples of the measurement results. In Example A, the temperature was around $26{ }^{\circ} \mathrm{C}$ with small fluctuations, whereas the humidity gradually increased from about 20 to $40 \%$ rh. In Example B, a humidity of about $20 \%$ rh was maintained throughout, though the temperature increased from an initial $24{ }^{\circ} \mathrm{C}$ and sometimes exceeded $28^{\circ} \mathrm{C}$. This temperature pattern was observed in four of the ten trips.

Figure 2 shows the range of temperature and humidity measured at the seat table. Each point in the figure corresponds to a 1 minute mean temperature and humidity, and the ellipse encloses the $95 \%$ confidence region. The mean temperature was $25.9^{\circ} \mathrm{C}\left(\mathrm{SD} \pm 0.87^{\circ} \mathrm{C}\right)$ and the mean humidity was $23.6 \% \mathrm{rh}(\mathrm{SD} \pm 7.4 \% \mathrm{rh})$. The $95 \%$ confidence region for the temperature was from 23.8 to $28.0^{\circ} \mathrm{C}$, while that of humidity was from 5.6 to $41.7 \% \mathrm{rh}$. It is known that local discomfort is experienced when there is a vertical air temperature difference between the head and feet of more than $3{ }^{\circ} \mathrm{C}$ [6]. Because the air temperature difference between the baggage rack (above the head) and the floor (near the feet) was almost always less than $3{ }^{\circ} \mathrm{C}$, it is considered that there is little risk of local discomfort due to the vertical air temperature difference in the vehicle cabins. 


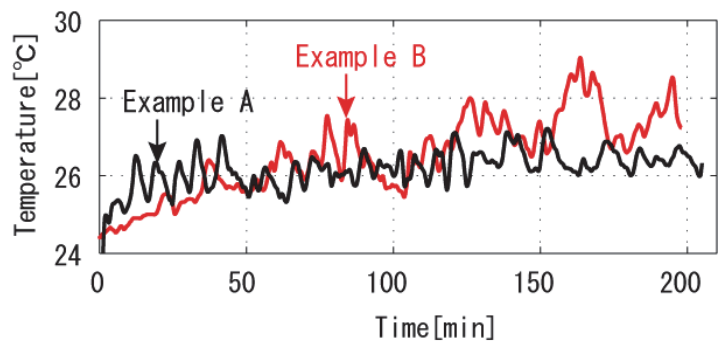

(a) Temperature

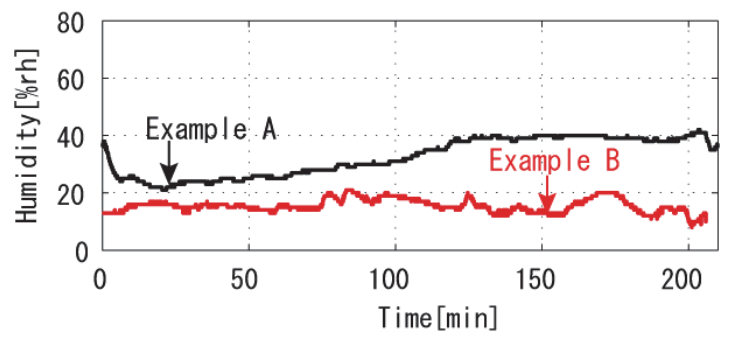

(b) Humidity

Figure 1: Two example measurement results measured at the seat table level near the centre of the cabin. Examples A and B correspond to Nos. 4 and 5 in Table 1 , respectively

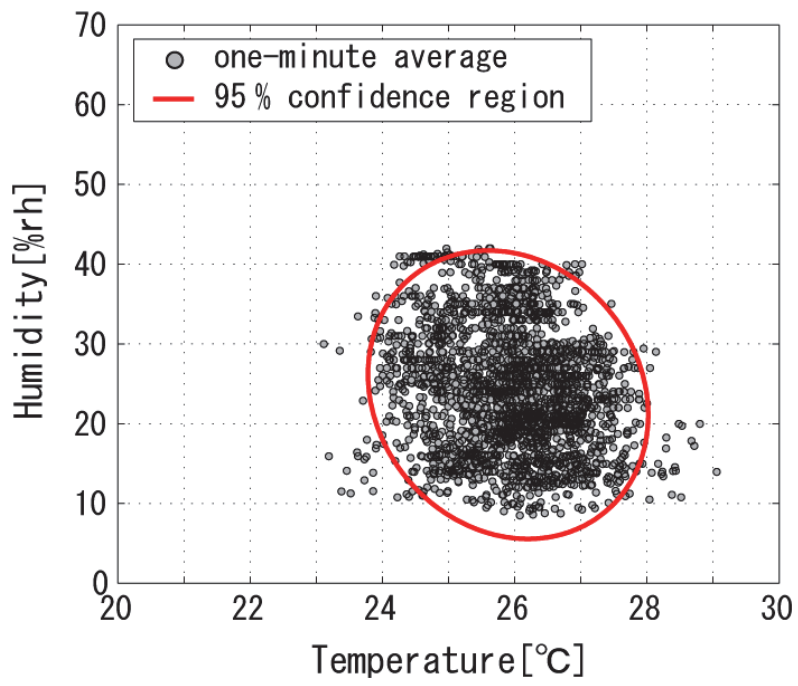

Figure 2: Observed range of temperature and humidity in a vehicle 


\section{Subjective experiment in a main line vehicle}

We conducted subjective experiments involving 19 participants (male: 9, female: 10, ages: 25-56). The experiments were conducted in the afternoon in the winter of 2014 in a stationary main line vehicle in the rolling stock centre. In the course of the experiment, the weather was rainy and the exterior temperature ranged $10.4-13.1{ }^{\circ} \mathrm{C}$, the humidity ranged $67-87 \% \mathrm{rh}$, and the amount of insolation from 0.006 to 0.010 $\mathrm{kW} / \mathrm{m}^{2}$. The experimental purpose was explained to the subjects, and their informed consent was obtained.

\subsection{Methods}

\subsubsection{Experimental conditions}

The initial cabin temperature was set to $24{ }^{\circ} \mathrm{C}$ and was maintained at this level for 35 minutes. Based on Example B in Figure 1, the cabin temperature was then increased. To obtain data across a wide temperature range, the upper temperature was set to $32{ }^{\circ} \mathrm{C}$, which was greater than the maximum temperature observed in the field studies. The schedule of the experiment is shown in Figure 3. Subjective evaluation began 15 minutes after the subjects entered the vehicle and was repeated at three-minute intervals. The subjects were allowed to rest for 15 minutes between the two parts of the experiment.

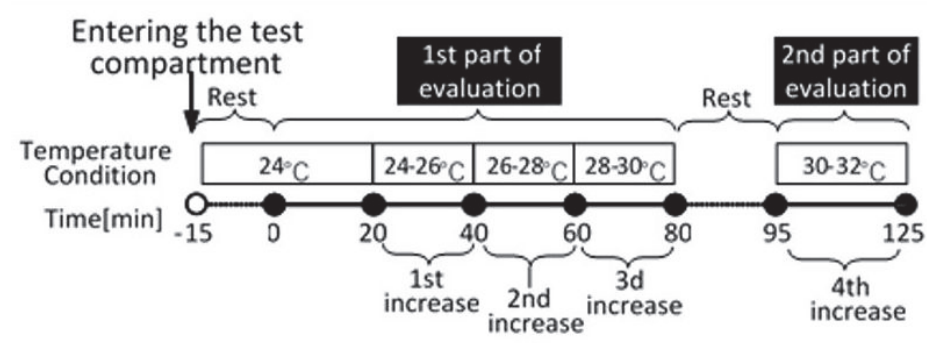

※ Time of 0 min means the start time of subjective evaluation.

Figure 3: Schedule of the subjective experiment

\subsubsection{Measurement of the thermal environment}

A thermometer and a hygrometer were set on the seat table of each subject, and temperature and humidity were measured in the same manner as that in the field studies.

To elucidate the vertical temperature distribution, we used thermistors (sensor: TR1106; logger: TR71Ui, T\&D) to measure the temperature at heights of $0.1,0.6$ and $1.1 \mathrm{~m}$ from the floor in $5 \mathrm{~s}$ intervals at the ends and the centre of the cabin. To estimate the intensity of thermal radiation, we used thermocouples set at the centre of the cabin 
to measure the surface temperatures of the floor, sidewalls, and ceiling at 1-s intervals. Figure 4 shows the arrangement of the sensors and subjects, and a schematic of the airflow in the cabin. The heated air moves from the underfloor mounted airconditioning unit to a longitudinal direction and is supplied to the cabin by passing through the vertical ducts installed within the side body structure of the vehicle on both sides. The heated air outlets are arranged at equal intervals in the longitudinal direction, and the heated air is blown from both side outlets. The interior air is extracted by the return ducts located on the floor and it is heated again in the airconditioning unit. Fresh air is taken from the outside at volume flow rate that is specified in JIS E 7103 [25] via forced ventilation. Volume flow rate of the inflowing warm air from the air conditioning unit is designed at about $120 \mathrm{~m}^{3} / \mathrm{min}$ in a vehicle.

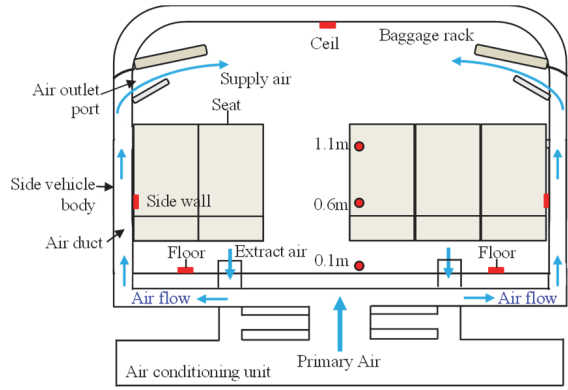

(a) Short section of the cabin

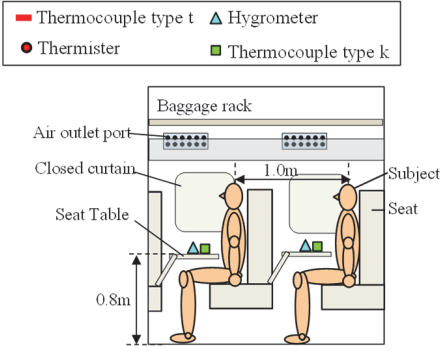

(b) A part of the longitudinal section of the cabin

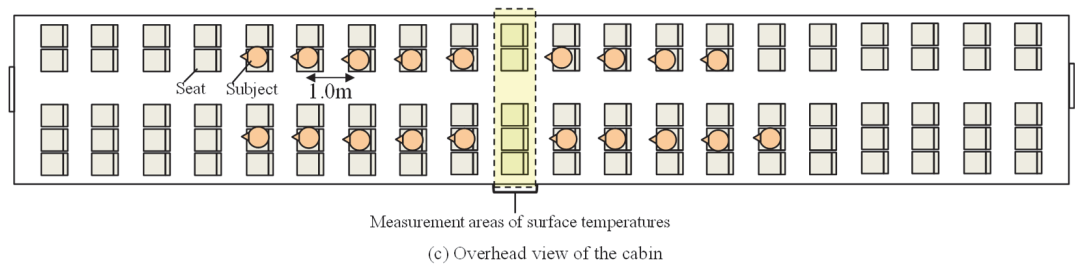

Figure 4: Arrangement of the measurement sensors and subjects

\subsubsection{Posture and clothing level}

The subjects were seated apart from one another and were allowed to adjust the backrest angle to achieve a relaxed posture. All subjects wore the same outer clothing. The experimental environment is shown in Figure 5.

\subsubsection{Subjective evaluation}

Three subjective evaluation items were considered: thermal sensation, sweat sensation, and thermal comfort. The degree of satisfaction with the thermal environment was also recorded. Evaluations were repeated at $3 \mathrm{~min}$ intervals. The evaluation scales are shown in Figure 6. While evaluating, subjects were asked to disregard non-thermal factors such as sounds or smells. While recording their degree of satisfaction, the subjects were asked to imagine that they were riding in a main line 
vehicle during regular service. This request was introduced to record the subjects' expectations of the thermal environment in a main line vehicle.

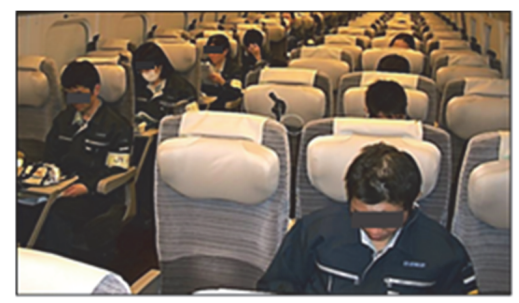

Figure 5: The subjective experiment

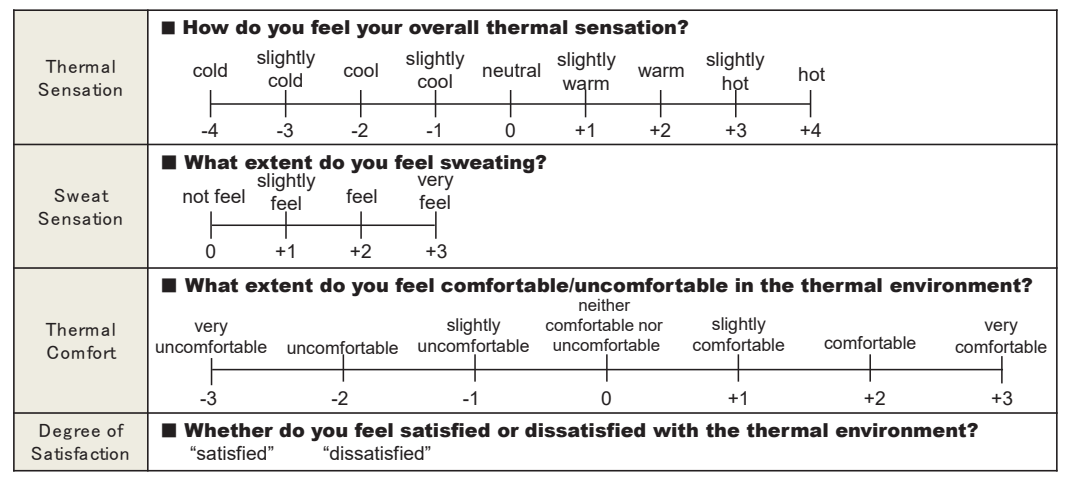

Figure 6. Scale of the subjective items

\subsection{Methods of analysis}

\subsubsection{Relation between the SET* and the subjective evaluations}

Human thermal comfort depends on six basic factors. Four of these factors are environmental: temperature, humidity, air velocity and radiant temperature, whereas two are personal: metabolic rate and insulation provided by clothing. The SET ${ }^{*}$ is one of the most widely used thermal indices that considers these six basic factors, and models 'the equivalent air temperature of an isothermal environment at $50 \% \mathrm{rh}$ in which a subject, wearing clothing standardised for the activity concerned, has the same heat stress and thermoregulatory strain as in the actual environment' [6]. It is calculated using body heat balance equations, which describe the heat exchanges between the skin surface and ambient environment.

In this study, SET* was calculated using Gagge's program [4]. A regression analysis was then conducted to derive the relational expressions between the SET and the subjective evaluations. These expressions were the mean thermal sensation (MTS); the percentage of sweat sensation (PSS) excluding 'not feel'; the percentage 
discomfort in the range -1: slightly uncomfortable to -3 : very uncomfortable (PUC) and the percentage dissatisfied (PD). Because a linear relation between the SET ${ }^{*}$ and MTS was established [21], MTS was represented as a linear model. The model parameters were identified by the least-squares method. In contrast, the PSS, PUC and PD express the percentage of the subjects, and these values will level off in the low/high SET ${ }^{*}$ region. Therefore, the PSS, PUC and PD were represented as a logistic regression model, and the model parameters were identified using the likelihood method. Statistical analysis was conducted using MATLAB.

\subsubsection{Relation between the PMV/PPD and subjective evaluation values}

PMV was introduced by Fanger [3] for use in buildings. In the PMV calculation, the thermal load from the ambient thermal environment is calculated based on steady state heat transfer theory, and then the mean value of the thermal sensations recorded by a large group on a 7-point scale (-3: cold, -2 : cool, -1 : slightly cool, 0 : neutral, +1 : slightly warm, +2 : warm, +3 : hot $)$ is predicted using the regression function calibrated against experimental data obtained in a climatic chamber in the autumn or winter $[26,27]$. The required input variables are the same six basic factors used in the SET*.

The PPD was proposed as a way of predicting the number of people likely to feel uncomfortably warm or cool and is calculated using the following equation:

$$
P P D=100-95 \cdot\left(-0.003353 \cdot P M V^{4}-0.2179 \cdot P M V^{2}\right)
$$

Whereas the SET* uses physiological values, the PMV and the PPD use psychological values that directly predict human thermal sensations and the degree of satisfaction. Because these values are easy to interpret, they are often used when human thermal comfort is estimated across a range of fields. It should be noted that the above equation was derived from thermal sensation data and not from satisfaction data. 'Thermally dissatisfied people' are defined by Fanger [3] as those who place themselves at +3 : hot, +2 : warm, -2 : cool or -3 : cold on the 7-point thermal sensation scale. These data are converted to a percentage and connected with the PMV values by Equation (1).

In this study, the PMV and PPD were calculated using the programs specified in ISO 7730 [5]. The relations between the PMV and the subjective evaluation values (MTS, PSS, PUC and PD) were analysed. The percentage of 'thermally dissatisfied people' (PD_thermal) was calculated using the above definition and compared with the PPD.

\subsection{Results}

\subsubsection{Thermal environments}

The time-series variation in temperature and humidity measured at the seat table is shown in Figure 7. At the point where the subjects were seated, the temperature varied by about 1 to $2{ }^{\circ} \mathrm{C}$ and the humidity by about $5 \%$ rh. Figure 7 (a) shows the average surface temperature, which was almost the same as the average air temperature; thus, thermal radiation from the peripheral walls was negligibly small. The vertical 
temperature distribution at heights of $0.1,0.6$ and $1.1 \mathrm{~m}$ is shown in Figure 8. The vertical temperature difference was less than $3{ }^{\circ} \mathrm{C}$.

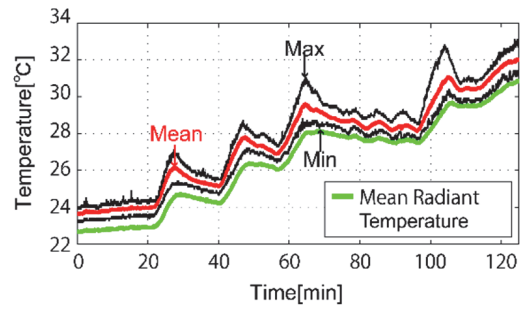

(a) Temperature

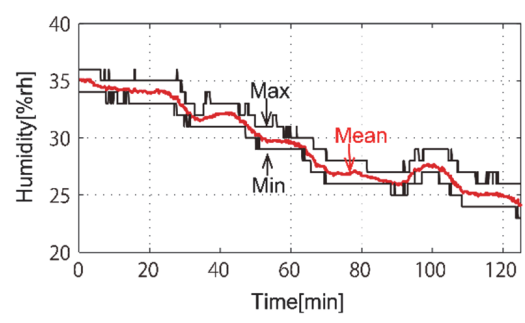

(b) Humidity

Figure 7: Temperature and humidity changes

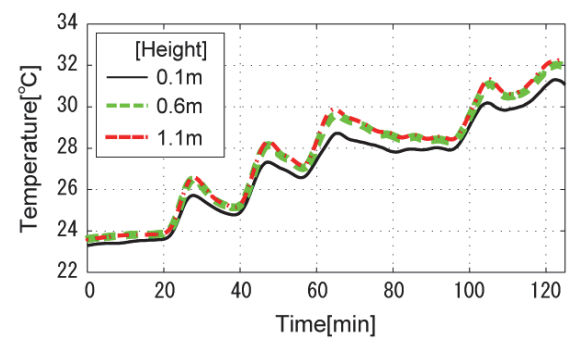

Figure 8: Temperature measured at $0.1,0.6$ and $1.1 \mathrm{~m}$ above the floor

\subsubsection{Subjective evaluations}

\section{(1) Time-series variations}

Figure 9 shows the time-series variation in the recorded MTS [Figure 9(a)]; the percentage recording discomfort from -1 : slightly uncomfortable to -3 : very uncomfortable [PUC, Figure 9(b)]; the percentage reporting a sweat sensation, excluding 'not feel' [PSS, Figure 9(c)], and the percentage of subjects who were dissatisfied with the thermal environment [PD, Figure 9(d)]. As seen in Figure 9, the MTS and the PUC changed corresponding to the change in cabin temperature after the first temperature increase. The PSS and the PD clearly changed after the second temperature increase. At the second temperature increase from 26 to $28{ }^{\circ} \mathrm{C}$, approximately 40 to $60 \mathrm{~min}$ after the start of the experiment, the PUC increased rapidly to $60 \%$. At the third temperature increase from 27 to $30{ }^{\circ} \mathrm{C}$, approximately 60 to 80 min after the start of the experiment, the PUC further increased to $70 \%$, the PSS increased from 20 to $50 \%$ and the PD increased to $60 \%$. At the fourth temperature increase from 30 to $32{ }^{\circ} \mathrm{C}$, approximately 100 to $125 \mathrm{~min}$ after the start of the experiment, all subjective evaluation values increased. 


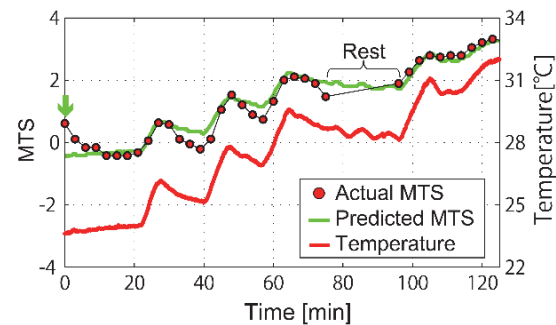

(a) Mean Thermal Sensation

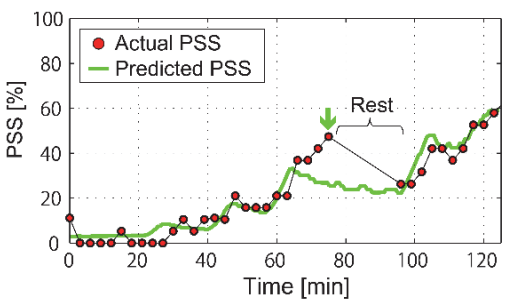

(c) Percentage of Sweat Sensation

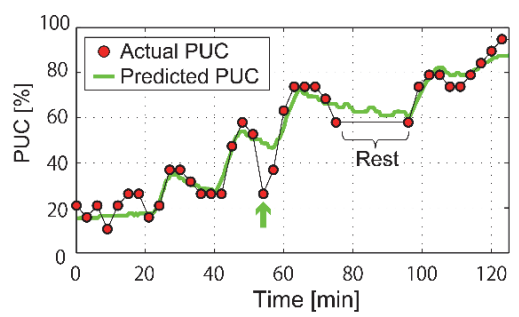

(b) Percentage of Uncomfortable Feeling

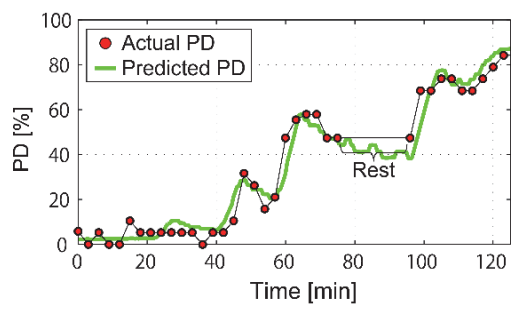

(d) Percentage of Dissatisfied

Figure 9: Time-series plots of subjective evaluations. The points that are significantly different than the predicted values from the regression equations are marked with arrows

\section{(2) Relations with the SET*}

Figure 10 shows the relation between the $\mathrm{SET}^{*}$ and the subjective evaluation values. The data input to the $\mathrm{SET}^{*}$ calculation program were the temperature and humidity measured at each seat table, an air velocity of $0.25 \mathrm{~m} / \mathrm{s}$ (the mean value measured in the empty cabin before the experiment), a mean radiant temperature estimated from surface temperatures and corresponding angle factors based on ISO 7726 [28], an activity rate of 1.0 met, corresponding to a relaxed sitting posture, and a clothing insulation of $1.1 \mathrm{clo}$, estimated from the clothing weight [29] and thermal insulation values for chairs [5]. Subjective evaluations were correlated with the corresponding $30 \mathrm{~s}$ averaged temperature at each answering time of the questionnaire because it took approximately $30 \mathrm{~s}$ to answer the subjective questions shown in Figure 6. In Figure 10 , it can be confirmed that the MTS has strong linear relationship with the SET ${ }^{*}$, in contrast, the PSS, PD and PUC have a nonlinear relationship with the SET*: the PSS and the PD begin to increase rapidly from around $27^{\circ} \mathrm{C}$ of SET ${ }^{*}$, and the PUC seems to change the increasing ratio around $27^{\circ} \mathrm{C}$ of SET ${ }^{*}$. The regression line and curves are also shown in Figure 10. The regression models were as follows:

$$
\begin{array}{ll}
\text { MTS }=0.64 \cdot \text { SET }^{*}-16.4 & (\mathrm{r}=0.97, \mathrm{p}<0.01) \\
P U C=100 /\left\{1+\exp \left(-0.63 \cdot S E T^{*}+17.4\right)\right\} & (\mathrm{r}=0.98, \mathrm{p}<0.01) \\
P S S=100 /\left\{1+\exp \left(-0.67 \cdot S E T^{*}+20.2\right)\right\} & (\mathrm{r}=0.98, \mathrm{p}<0.01) \\
P D=100 /\left\{1+\exp \left(-0.98 \cdot S E T^{*}+28.3\right)\right\} & (\mathrm{r}=0.98, \mathrm{p}<0.01)
\end{array}
$$


where $r$ is the correlation between the actual mean or percentage values and the predicted values. They accurately represent the total trends in the recorded subjective values. However, it can be confirmed that some points have relatively large difference with the regression lines: for example, around $24.5^{\circ} \mathrm{C}$ of SET ${ }^{*}$ in Figure 10 (a), around $27.5^{\circ} \mathrm{C}$ of SET ${ }^{*}$ in Figure 10 (b) and around $28.5^{\circ} \mathrm{C}$ of SET ${ }^{*}$ in Figure 10 (c) (they are marked with arrows in Figure 10). To clarify when those deviation occurred, the predicted values based on Equations (2) to (5) were shown in Figure 9. Regarding the MTS, PUC and PSS, the large deviations from the predicted values occurred at the first evaluation $(0 \mathrm{~min})$, the 19th evaluation (around $55 \mathrm{~min}$ : the last part of the second temperature increase), and the $25 \mathrm{th} / 26$ th evaluation (around $75 \mathrm{~min}$ : the last part of the third temperature increase), respectively (they are marked with arrows in Figure 9).

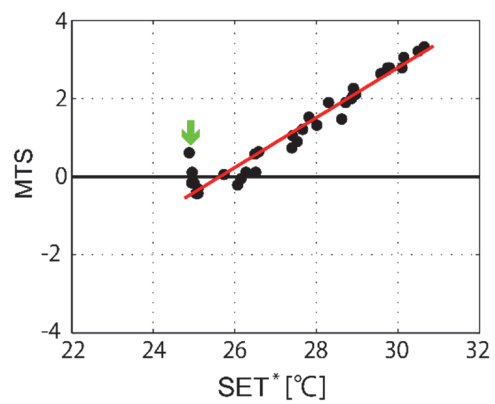

(a) Mean Thermal Sensation

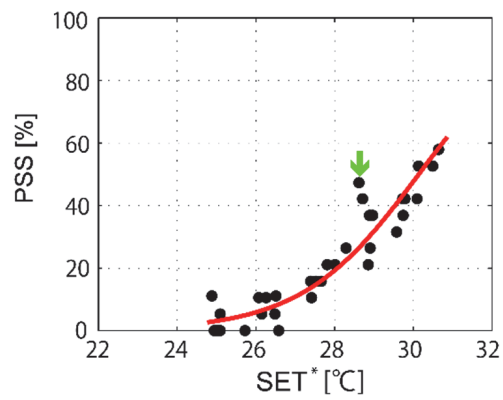

(c) Percentage of Sweat Sensation

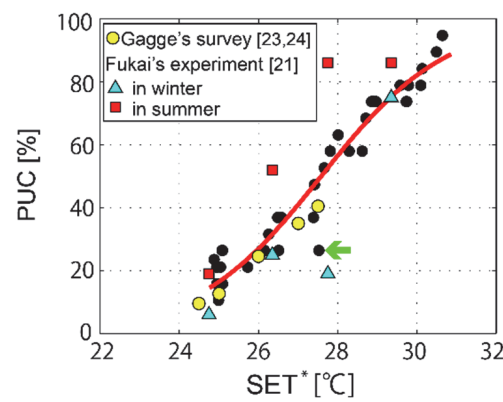

(b) Percentage of Uncomfortable Feeling

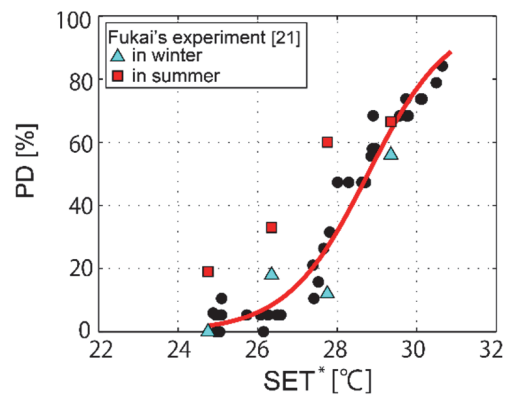

(d) Percentage of Dissatisfied

Figure 10: Relations between the SET ${ }^{*}$ and subjective evaluations. The points that have a large difference with the regression line are marked with arrows

\section{(3) Relation with the PMV and PPD}

Figure 11(a) shows the relation between the PMV (7-point scale) and MTS (9-point scale). The regression line passes near the origin, the neutral points are almost coincident $(95 \%$ confidence interval of $\mathrm{Y}$-intercept is -0.222 to +0.001 , which contains 0 ), and PMV $=2$ ('warm') corresponds to MTS $=3$ ('slightly hot' in 
Japanese). Using this relation between the PMV and MTS, the percentage of 'thermally dissatisfied people' defined by Fanger [3] may be calculated as the percentage who recorded thermal sensations of +3 : slightly hot or +4 : hot on the 9point scale used in our experiment.

Figure 11(b) shows the relation between the PMV and PSS, PUC, PD, and PD_thermal. The root-mean-square errors of the PPD for the PUC, PD, and PD_thermal were $24.0,11.0$, and $6.5 \%$, respectively. Of the three subjective evaluation items, the PD_thermal was closest to the PPD.

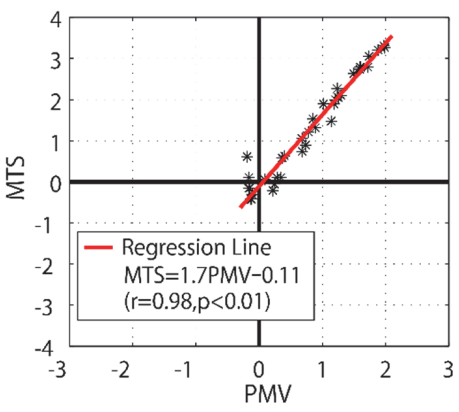

(a) Mean Thermal Sensation

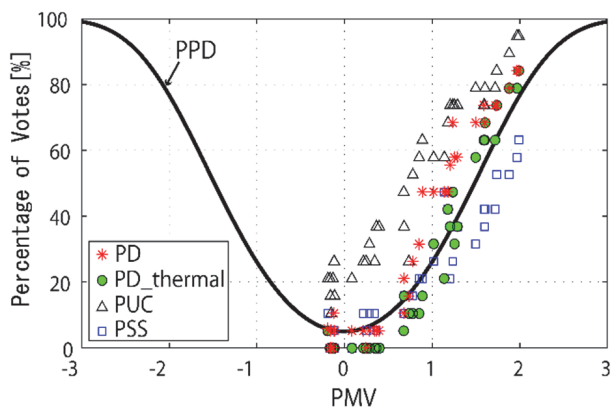

(b) PD, PD_thermal, PUC and PSS

Figure 11: Relation between the PMV and the subjective evaluations

\subsection{Discussion}

\subsubsection{Comparison with results from climatic chamber tests}

Fukai et al. [21] investigated the relation between the SET ${ }^{*}$ and the thermal comfort of Japanese subjects in a climatic chamber in winter and summer. In both the summer and winter experiments, 14 subjects (male: 7, female: 7) in sitting positions were exposed to 31 different conditions representing SET ${ }^{*}$ values ranging $18-29{ }^{\circ} \mathrm{C}$. The subjects recorded their thermal comfort under each condition, after one hour. The subjective evaluation items and scales were those used in our experiment.

The PUC and PD from Fukai's experiment are shown in Figures 10(b) and (d), respectively. In the winter experiment, both the PUC and PD were similar to those from our experiment, suggesting that the expectations of the thermal environment in a main line vehicle are similar to those of a building. This result further suggests that the findings of climatic chamber tests are applicable to main line vehicles.

As shown in Figures 10(b) and (d), in Fukai's experiment, the relation between the SET $^{*}$ and PUC or PD depended on the season. This seasonal characteristic of thermal comfort may also be applicable to passengers in a main line vehicle. However, because few studies have been conducted on the seasonal characteristics of thermal comfort, subjective experiments conducted in different seasons are needed to elucidate these characteristics. 


\subsubsection{Comfort/Satisfaction range of $\mathrm{SET}^{*}$}

We subsequently compared our results with those of survey by Gagge [23] that was used to derive ASHRAE's SET* comfort range of 22.2-25.6 ${ }^{\circ} \mathrm{C}$ [24]. We also investigated the comfort/satisfaction range of the $\mathrm{SET}^{*}$ in a main line vehicle in winter.

In Gagge's survey, questionnaires were distributed to office workers in a New York government building. Although surveys were conducted in both summer and winter, only the winter data were used to set the comfort range of the SET* ${ }^{*}$ The subjective item 'Comfortable/Uncomfortable' was used to evaluate thermal comfort, and the relation between the $\mathrm{SET}^{*}$ and the percentage of 'Uncomfortable' votes (corresponding to the PUC in our study) was examined.

Figure 10(b) shows the percentage of thermally uncomfortable people at an SET range greater than $24^{\circ} \mathrm{C}$. As can be seen, the PUC in our experiment was close to the corresponding results of the Gagge study. However, while the upper bound could be estimated in our study, the lower bound could not be estimated because the SET ${ }^{*}$ value was higher than $24^{\circ} \mathrm{C}$ in the experimental condition. If the comfort range is defined as the SET $^{*}$ range in which the PUC is less than $20 \%$, the upper bound derived from our experiment is estimated at $25.4^{\circ} \mathrm{C}$, which is very close to ASHRAE's value of $25.6^{\circ} \mathrm{C}$. This suggests that the SET ${ }^{*}$ of ASHRAE is also applicable to a main line vehicle in winter.

However, if the 'satisfaction range' is defined as the SET" range in which the PD is less than $20 \%$, the upper bound is estimated to be $27.5^{\circ} \mathrm{C}$. This result suggests that while more than $20 \%$ of the subjects felt some degree of thermal discomfort in the SET $^{*}$ range $25.4-27.5^{\circ} \mathrm{C}$, some subjects found the thermal environment acceptable. The rapid increase in the PSS at an SET ${ }^{*}$ of around $28{ }^{\circ} \mathrm{C}$ suggests that the thermal environment in a main line vehicle in winter should be maintained at an SET ${ }^{*}$ lower than $27.5^{\circ} \mathrm{C}$. Though the lower bound could not be estimated in this study, the same idea may apply to the lower bound: the lower bound of the satisfaction range may be lower than that of the comfort range.

Given the considerations described above, the 'satisfaction range' is considered to be wider than the 'comfort range', and the difference between the two ranges would represent the degree of expectation of passengers: if the difference is small, the expectation may be high; if the difference is large, the expectation may be low. The difference may depend on the vehicle types and the seasons. It is important to understand both ranges because these ranges would provide useful information to control the thermal environment by considering a balance between passengers' thermal comfort and energy conservation for air-conditioning systems in railway vehicles. To comprehensively understand the year-round comfort/satisfaction range in various vehicle types, subjective experimental data should be collected in each season and vehicle type. Collection of this data is our future work. 


\subsubsection{Effects of the non-stationarity of the thermal environment}

The thermal environment in the subjective experiment was non-stationary. Regarding the effects of the non-stationarity of the thermal environment, it was reported that after an up-step in temperature, the new steady-state thermal sensation was experienced immediately, and in contrast, after a down-step in temperature, the new steady-state thermal sensation was experienced after approximately 30 minutes $[5,30]$. In this study, the relation between thermal environments (non-stationary) and subjective evaluations were well expressed by Equations (2)-(5). This result may be due to the fact that the temperature mainly increased in the experiment. Therefore, as seen in Figures 9(a) and (b), the prediction accuracies of the regression equations are reduced in the temperature-decreasing condition.

It is also generally known that the beginning of the perspiration is relevant to the skin temperature whose response is delayed corresponding to the sudden temperature changes because of the thermal capacity of the human body [20]. In Figure 9(c), we can see that the PSS increases with some delay for each temperature increase. Accordingly, it is inferred that the relatively high PSS just before the "Rest" (about $50 \%$ ) was affected by the third temperature increase whose maximum temperature was around $31{ }^{\circ} \mathrm{C}$ (see Figure 8 (a)), and the relatively low PSS just after the rest (about $25 \%$ ) was affected by the stationary temperature around $28^{\circ} \mathrm{C}$ during the rest.

Moreover, non-stationarity of the metabolic rate may have affected the subjective ratings. For example, in the subjective experiment, the walking activity of the subjects before entering the test vehicle would affect their metabolic rate, even after they sat down on the seats. We can see this effect during the first few minutes of the MTS results in Figure 9(a) (0 to $10 \mathrm{~min}$ ), where MTS decreased gradually even though the temperature was almost constant. This result indicates that in non-stationary conditions of metabolic rate; for example, when passengers just get on a train the prediction accuracies of the regression equations are reduced if the metabolic rate is set to 1.0 met (sedentary activity) to calculate SET* .

\subsubsection{Relations between the PPD and subjective evaluation values}

As discussed in Section 3.3.2, PPD was closer to PD_thermal than PUC or PD. This proximity seems intuitive because the PD_thermal was derived using thermal sensation ratings, which is the same manner as the PPD calculation defined by Fanger [3]. However, PPD was lower than PD at PMV $\geq 0.8$. We assume that this difference was caused by the increase in PSS. Thermal comfort is known to be influenced not only by thermal sensations but also by sweating [4]. For PMV $\geq 0.8$, discomfort most likely arises from both the sensation of warmth and sweating. This hypothesis explains the difference between the PPD and PD: as the PPD was derived only from thermal sensation ratings, it underestimated the PD. PUC was much higher than PPD as well as PD and PD_thermal, especially for PMV $<0.8$. The PUC was more sensitive to heat stress because it increased when the subjects rated the thermal environment as slightly uncomfortable (as mentioned before, the PUC is the percentage of subjects recording discomfort from -1 : slightly uncomfortable to -3 : very uncomfortable), even 
if they rated the environment as satisfying. Figure 11(b) indicates that the psychological evaluation values were strongly influenced by the rating scales.

We now consider whether PPD is applicable to a main line vehicle. PPD is able to predict the overall trend of $P D$, but for $P M V \geq 0.8$, in which perspiration would begin, the prediction error would become large. It was reported that Japanese people experience increased sweating in summer [20]; thus, the prediction error of PPD would become larger in summer. However, PPD agreed well with PD thermal, even in the range $\mathrm{PMV} \geq 0.8$. It was reported that the relation between the $\mathrm{SET}^{*}$ and thermal sensation in winter is the same as that in summer [21]. This relation would allow PPD to be used as an index of the variability in the thermal sensation of passengers. However, if a higher level of predictive accuracy is required throughout the year, however, PPD would be a poor index.

\subsubsection{Application of the regression equations obtained in this study}

The regression equations obtained in this study can be applied to the quantitative estimation of the thermal sensation and comfort of passengers in a main line vehicle. For example, Figure 12 shows the estimated MTS and PD obtained by applying Equations (2)-(5) to Example B from Figure 1. While calculating SET*, the input values for clothing insulation were set to 1.1 and 0.8 clo. For reference, a value of 1.1 clo corresponds approximately to a winter business suit (and also to the clothes used in the subjective experiment, as shown in Figure 5). If the suit jacket is removed, the clothing insulation is approximately 0.8 clo. Other input values were set to the same values as those used in the subjective experiment. The results suggest that if passengers are wearing winter business suits, their thermal sensation after 125 min from the departure time would be slightly warm to warm, and PD would be greater than $20 \%$. If jackets are removed, their thermal sensation would be near neutral and the PD would be less than $20 \%$. Therefore, the thermal sensation and comfort of passengers in various situations can be estimated quantitatively by applying the regression equations obtained in this study, with both environmental and personal factors accounted for.

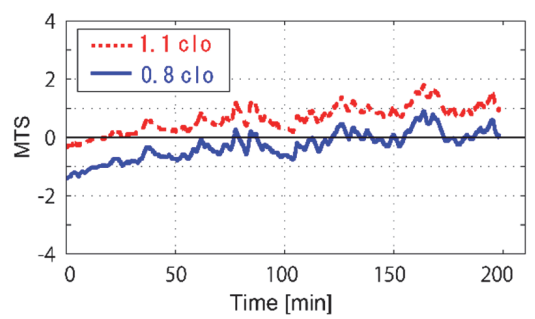

(a) Mean Thermal Sensation

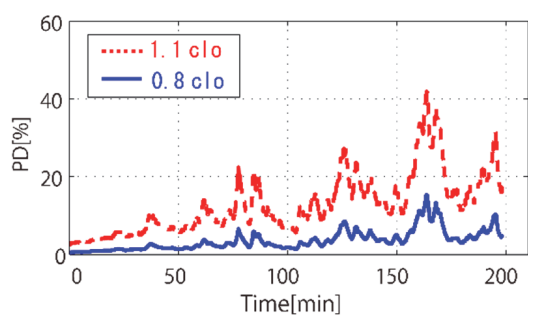

(b) Percentage of Dissatisfied

Figure 12: Estimation of thermal sensation and the percentage of dissatisfied subjects with the thermal environment shown in Example B of Figure 1 


\subsubsection{Limitations of this study}

This study investigated thermal comfort in a thermally uniform environment. In reality, however, passengers are sometimes exposed to non-uniform environments; for example, receiving insolation from the window on a part of the body [31]. Such non-uniform environments are beyond the scope of Equations (2) to (5). In addition, as mentioned Section 3.4.3, when the thermal environment is non-stationary, the prediction accuracies of the equations would become worse. The temperature condition of the vehicle in the experiment was more than $23{ }^{\circ} \mathrm{C}$. Lower-temperature conditions are needed to clarify the lower bound of the comfort and satisfaction range. Furthermore, the experiment was conducted in a vehicle at standstill; thus, noise and vibrations were non-existent. These factors may affect the thermal comfort of passengers in moving vehicles.

Investigating how these factors affect the thermal comfort of passengers in running trains is a future task.

\section{Conclusions}

In this study, field measurements and subjective experiments were performed to clarify the relation between subjective data reflecting passengers' expectations of thermal comfort in main line vehicles and the calculated thermal indices (PMV/PPD and $\mathrm{SET}^{*}$ ) in Japan in winter. The main results and findings of this study are as follows:

- In field measurements conducted in main line vehicles in winter, the observed range of temperatures was $23.8-28.0^{\circ} \mathrm{C}$, and that of humidity was $5.6-41.7 \% \mathrm{rh}$. The vertical air temperature difference between the head and feet was usually within $3{ }^{\circ} \mathrm{C}$.

- Regression analysis of the relations between the SET ${ }^{*}$ and subjective evaluations was carried out, based on the results of a subjective experiment conducted in a main line vehicle in winter. Predicted values from the regression equations showed a strong correlation with actual values, suggesting that these regression equations may be used for quantitative estimation of the thermal sensations and comfort of passengers in a main line vehicle in winter.

- The relations between the $\mathrm{SET}^{*}$ and thermal comfort found in our experiment were similar to those found in a climatic chamber in winter, but were different from those found in summer. This suggests that findings from climatic chamber tests are applicable to main line vehicles, but that seasonal variations in thermal comfort should be taken into account.

- The upper bound of the comfort range of the $\mathrm{SET}^{*}$ in a main line vehicle in winter was estimated to be $25.4^{\circ} \mathrm{C}$, a temperature that closely matches the ASHRAE value of $25.6{ }^{\circ} \mathrm{C}$. 
- If the 'satisfaction range' is defined as the $\mathrm{SET}^{*}$ range at which the percentage of thermally dissatisfied people is less than $20 \%$, the upper bound can be estimated at $27.5^{\circ} \mathrm{C}$. At around this $\mathrm{SET}^{*}$ range, reports of a sweating sensation began to rapidly increase. This suggests that the thermal environment in a main line vehicle in winter should be maintained at an SET* lower than $27.5^{\circ} \mathrm{C}$.

- The error in PPD while predicting the percentage of dissatisfied subjects became large for $\mathrm{PMV} \geq 0.8$, in which the sweating sensation was observed to increase significantly. However, the PPD agreed well with the actual percentage of people who reported feeling slightly hot or hot. Our results suggest that the PPD can be used as an index of the variability of thermal sensation, but not of thermal comfort.

\section{References}

[1] H. Suzuki, H. Shiroto, K. Omino, "Identification of Factors Determining Comfort of Train", Railway Technical Research Report, 11, 31-36, 1997 (in Japanese).

[2] European Committee for Standardization, EN 13129 "Railway Applications Air Conditioning for Main Line Rolling Stock - Comfort Parameters and Type Tests", 2016.

[3] P.O. Fanger, "Thermal Comfort”, McGraw-Hill, 1972.

[4] A.P. Gagge, A.P. Fobelets, L.G. Berglund, "A Standard Predictive Index of Human Response to the Thermal Environment", AHSHRAE Transactions, 92, 709-731, 1986.

[5] International Standard Organization, ISO7730 "Ergonomics of the Thermal Environment-Analytical Determination and Interpretation of Thermal Comfort Using Calculation of the PMV and PPD Indices and Local Thermal Comfort Criteria", 2005.

[6] American Society of Heating, Refrigerating and Air-Conditioning Engineers, ANSI/ASHRAE Standard55-2004, "Thermal Environmental Conditions for Human Occupancy”, 2004.

[7] L. Pang, Y. Qin, D.Lin, M. Liu, ’Thermal Comfort Assessment in Civil Aircraft Cabins", Chinese Journal of Aeronautics, 27 (2), 210-216, 2014.

[8] K. Zhang, K. Zhou, F. Zhang, "Evaluating Bus Transit Performance of Chinese Cities: Developing an Overall Bus Comfort Model", Transportation Research Part A, 69, 105-112, 2014.

[9] U. Pala, H.R. Oz, "An Investigation of Thermal Comfort Inside a Bus during Heating”, Appl. Ergon. 48, 164-176, 2015.

[10] T.P. Lin, R.L. Hwang, K.T. Huang, C.Y. Sun, Y.C. Huang, "Passenger Thermal Perceptions, Thermal Comfort Requirements, and Adaptations in Short- and Long-haul Vehicles", Int. J. Biometeorol. 54 (3), 221-230, 2010.

[11] G. Katavoutas, M.N. Assimakopoulos, D.N. Asimakopoulos, "On the Determination of the Thermal Comfort Conditions of a Metropolitan City Underground Railway", Science of Total Environment, 566-567, 877-887, 2016. 
[12] P. Underwood, K.C. Parsons, "Discomfort Caused by Sitting Next to a Cold Window. Simulated Railway Carriage at Night", Comtemporary Ergonomics, 232-238, 2005.

[13] L.K. Kelly, "Thermal Comfort on Rail Journeys", PhD Thesis, Department of Human Sciences, Loughborough University, 2011.

[14] H. Zhang, E. Arens, C. Huizenga, T. Han, "Thermal Sensation and Comfort Models for Non-uniform and Transient Environments: Part I: Local Sensation of Individual Body Parts", J. Building and Environment 45, 380-388, 2010.

[15] H. Zhang, E. Arens, C. Huizenga, T. Han, "Thermal Sensation and Comfort Models for Non-uniform and Transient Environments: Part II: Local Comfort of Individual Body Parts", J. Building and Environment 45, 389-398, 2010.

[16] D. Fiala, K.J. Lomas, M. Stohrer, "A Computer Model of Human Thermoregulation for a Wide Range of Environmental Conditions: the Passive system", J. Appl. Phisiol. 87(5), 1957-1972, 1999.

[17] D. Fiala, K.J. Lomas, M. Stohrer, "Computer Prediction of Human Thermoregulatory Responses to a Wide Range of Environmental Conditions", Int. J. Biometeorol. 45, 143-159, 2001.

[18] M. Konstantinov, C. Wagner, "Numerical simulation of the thermal comfort in train cabin", International Journal of Railway Technology, 4 (3), 69-88, 2015.

[19] J. Nakano, K. Sakamoto, T. Iino, S. Tanabe, "Thermal Comfort Conditions in Train Stations for Transit and Short-Term Occupancy", in "Proceedings on Comfort and Energy Use in Buildings_-Getting Them Right", Windsor, 2006.

[20] T. Nakayama, "Thermophysiology", Rikogakusha, 1981 (in Japansese).

[21] K. Fukai, S. Gotoh, J. Saito, H. Ito, S. Akui, "Experimental Study on Correlation between Standard New Effective Temperature (SET*) and Japanese Thermal Sensation: Part 2-Comparison of Thermal Sensation in Winter and Summer Seasons", SHASE, 51, 139-147, 1993 (in Japanese).

[22] H. Endoh, F. Kikuchi, Y. Izumi, S. Tsujimura, N. Hayashi, "Experimental Study on Thermal Comfort in Railway Vehicle", in "The Proceedings of the 7th International Symposium on Speed-up and Sustainable Technology for Railway and Maglev Systems", 2015.

[23] A.P. Gagge, R.G. Neveins, "Effect of Energy Conservation Guidelines on Comfort, Acceptability and Health", NBS Special publication 491, Thermal Analysis-Human Comfort-Indoor Environments, 1977.

[24] The Society of Heating, Air-Conditioning and Sanitary Engineers of Japan, "Mechanism of Comfortable Thermal Environment", Maruzen publishing, 2006 (in Japanese).

[25] Japanese Industrial Standards Committee, JIS E 7103 "Rolling stock - General Requirments of Carbody for Passenger Car", 2006.

[26] R.G. Nevins, F.H. Rohles, W. Springer, A.M. Feyerherm, "A TemperatureHumidity Chart for Thermal Comfort of Seated Persons", ASHRAE Trans., 72, 283-291, 1966.

[27] P.E. McNall, J. Jaax, F.H. Rohles, R.G. Nevins, W. Springer, "Thermal Comfort (Thermally Neutral) Conditions for Three Activity Levels", ASHRAE Trans., 73, I.3.1-I.3.14, 1967. 
[28] International Standard Organization, ISO7726 "Ergonomics of the Thermal Environment - Instruments for Measuring Physical Quantities", 1998.

[29] K. Hanada, K. Mihira, Y. Sato, "Studies on the Thermal Resistance of Men's Underwears", Journal of Japan Research Association for Textile End-Uses, 24 (8), 363-369, 1983 (in Japanese).

[30] R.J. de Dear, J.W. Ring, P.O. Fanger, "Thermal Sensations Resulting from Sudden Ambient Temperature Changes", Indoor Air, 3, 181-192, 1993.

[31] S.G. Hoodder, K.C. Parsons, "The Effects of Solar Radiation on Thermal Comfort”, International Journal of Biometeorology, 51, 233-250, 2007. 